\title{
Tecnologia alternativa para a quebra de dormência das sementes de pau-de-balsa (Ochroma lagopus Sw., Bombacaceae).
}

\author{
Antenor P. BARBOSA ${ }^{1}$; Paulo de .T. B. SAMPAIO ${ }^{1}$; Moacir. A. A. CAMPOS ${ }^{1}$; Vânia P. VARELA ${ }^{1}$; Cláudia de Q. B. \\ GONÇALVES $^{1}$; Shigeo IIDA² .
}

\begin{abstract}
RESUMO
Este trabalho, teve como objetivo estudar a germinação das sementes de pau-de-balsa (Ochroma lagopus Sw., Bombacaceae) em diferentes estágios de maturação aparente dos frutos; a germinação das sementes provenientes de árvores com diferentes diâmetros a altura do peito (DAP) e a germinação das sementes tratadas para quebra de dormência. No primeiro experimento, avaliou-se a germinação das sementes dos frutos verdes, verdosos (verde amarelado), negros (fruto fechado) e negros deiscentes (fruto aberto com painas expostas). No segundo, a germinação das sementes de árvores da mesma idade e com diferentes DAP's: pequeno $(5,4 \mathrm{~cm})$, médio $(9,1 \mathrm{~cm})$ e grande $(13,2 \mathrm{~cm})$. No terceiro, a germinação das sementes com diferentes quebra de dormência: testemunha; água por 24 e 48 horas; água a $80^{\circ} \mathrm{C}$ até esfriar; $\mathrm{H}_{2} \mathrm{SO}_{4}$ por ${ }^{1 / 2}$ e 1 minuto com e sem paina; queima da paina em peneira metálica; e semeio de sementes com a paina. As sementes germinaram em gerbox sobre papel de filtro, em câmara de germinação, nas temperaturas de $20^{\circ} \mathrm{C}, 30^{\circ} \mathrm{C}$ e $25^{\circ} \mathrm{C}$, no primeiro, segundo e terceiro experimentos, respectivamente. As sementes de pau-de-balsa germinaram melhor e mais rápido quando coletadas de frutos negros a negros deiscentes, ou quando coletadas de árvores com menor e médio diâmetros, ou quando tratadas com água quente a $80^{\circ} \mathrm{C}$ até esfriar, ou com ácido sulfúrico por $1 / 2$ ou 1 minuto com ou sem paina. Os tratamentos com ácido tem a vantagem de quebrar a dormência da semente e dissolver a paina. As sementes recém colhidas e germinadas não apresentaram dormência tegumentar.
\end{abstract}

PALAVRAS-CHAVE

Ochroma lagopus, dormência, sementes florestais, germinação.

\section{Alternative technology for breaking dormancy of balsa wood (Ochroma lagopus Sw., Bombacaceae) seeds.}

\begin{abstract}
The objective of this study was to evaluate the germination of balsa wood (Ochroma lagopus Sw., Bombacaceae) seed as a function of maturation stages of fruits, the germination of seeds harvested from trees with different diameters at breast height (DBH), and the germination of seeds with different treatments to break dormancy. In the first experiment, the germination of seeds from fruits of different maturation stages, green, greenish (green yellowish), black (closed fruit) and dehiscent black (fruit opened with displayed seed cotton), was evaluated. In the second, the germination of seeds from trees with the same age (17 months) and with different DBH, small $(5.4 \mathrm{~cm})$, medium $(9.1 \mathrm{~cm})$ and large $(13.2 \mathrm{~cm})$ was evaluated. In the third, the germination of seeds subjected to dormancy breaking treatments, control, water for 24 and 48 hours, water at $80^{\circ} \mathrm{C}$ and left to cool, $\mathrm{H}_{2} \mathrm{SO}_{4}$ for $1 / 2$ and 1 minute and with and without seed cotton; seed cotton burned on metallic sieve, and sowing of seeds with seed cotton was evaluated. The seeds were germinated on paper in germination chambers at $20^{\circ} \mathrm{C}, 30^{\circ}$ and $25^{\circ} \mathrm{C}$ in the first, second and third experiments, respectively. The balsa wood seeds germinated better and faster when the fruits were black or black debiscent, or when collected on trees with small or medium diameter, or treated with water at $80^{\circ} \mathrm{C}$, or treated with sulfuric acid for 1/2 or 1 minute with or without seed cotton. The treatment with sulfuric acid has the advantage to breaking dormancy and dissolving the seed cotton. The seeds newly collected and germinated no presented seedcoat dormancy.
\end{abstract}

\section{KEY WORDS}

Ochroma lagopus, seed dormancy, forest seed, germination.

\footnotetext{
${ }^{1}$ Instituto Nacional de Pesquisas da Amazônia/INPA - Coordenação de Pesquisas em Silvicultura Tropical (CPST). Cx. Postal 478, CEP 69.083-000, Manaus, AM, Brasil. 2 Perito FFPRI/JICA.
} 


\section{ACTA \\ AMAZONICA}

TECNOLOGIA ALTERNATIVA PARA A QUEBRA DE DORMÊNCIA

DAS SEMENTES DE PAU-DE-BALSA (Ochroma lagopus SW., BOMBACACEAE)

\section{INTRODUÇÃO}

A exploração madeireira na região Amazônica tem como uma das principais característica, a falta ou reduzida reposição das espécies exploradas. Esta característica, no longo prazo, faz com que aumentem as possibilidades de esgotamento do potencial madeireiro existente, além de uma grave erosão genética dessas espécies. A baixa capacidade de reposição florestal está associada, entre outros fatores, às poucas informações das técnicas silviculturais de produção de sementes e mudas das espécies nativas.

Entre as espécies arbóreas com potencialidade de uso para reflorestamento, o pau-de-balsa, apresenta importância ecológica, como uma espécie pioneira (Vasquez-Yanes, 1974) e, portanto, fazendo parte da sucessão florestal e, também, pela importância econômica dos diversos usos da madeira. A madeira pode ser utilizada para fabricação de papel e celulose, confecção de embarcações, forros de tetos (Loureiro \& Silva, 1968), é bom isolante térmico e serve para caixas de embalagem de produtos perecíveis (Rizzini, 1978) e um alto potencial na fabricação de chapas de cimento-madeira para divisórias, móveis, pisos, etc., com madeira de plantas com cerca de um ano de idade.

Segundo Vazquez e Yanes (1976), a espécie Ochroma lagopus, por suas características morfológicas, possui dormência tegumentar. A dormência em sementes representa um grande problema, pois dificulta a produção uniforme de mudas tanto de regeneração natural, quanto em viveiro.

Estudos sobre a geminação e métodos de análise em laboratórios, efetuados sob condições controladas, têm sido conduzidos no sentido de se obter dados mais completos de germinação de diversas espécies (Brasil, 1992). Entretanto, sobre as espécies que apresentam dormência, devem ser desenvolvidos estudos mais específicos, com o objetivo de aumentar, acelerar e uniformizar o processo da germinação.

Segundo Tulstrup \& Magine (1956) e Alves (1982), a germinação das sementes de Ochroma lagopus, ativa-se notavelmente quando colocadas submersas por 12 horas em água de côco. Loureiro (1979) salientou que para reduzir o período de germinação é necessário usar água fervente não fornecendo maiores informações. Existem recomendações quanto ao uso de tratamentos com ácido sulfúrico para acelerar a germinação de espécies que apresentam dormência tegumentar (Freitas \& Cândido, 1972).

A dureza e a impermeabilidade do tegumento são fatores que caracterizam a dormência das sementes da espécie em estudo. No entanto, o beneficiamento das sementes do paude-balsa é muito trabalhoso, por serem pequenas e aderidas à paina dificultando o processo de beneficiamento. Considerando estes fatores, este trabalho visou determinar tecnologias alternativas para a quebra da dormência e verificar a interferência da paina na germinação, avaliar o efeito da maturação aparente dos frutos e a influência do tamanho (DAP) das matrizes na germinação das sementes de Ochroma lagopus.

\section{MATERIAL E MÉTODOS}

As sementes de Ochroma lagopus utilizadas neste trabalho, foram coletadas de árvores matrizes plantadas no espaçamento de $3 \times 3$ m, no ramal Boa Esperança, BR 174, km 120, município de Presidente Figueiredo, AM. O trabalho foi composto por 3 experimentos e instalados no laboratório de sementes da Coordenação de Pesquisas em Silvicultura Tropical do Instituto Nacional de Pesquisas da Amazônia (CPST/INPA).

Experimento 1 - Foram utilizadas sementes de frutos em diferentes estágios de maturação aparente: verde, verdoso (verde amarelado), negro (fruto fechado) e negro deiscente (fruto aberto com painas expostas). As sementes foram retiradas das painas manualmente e colocadas para germinar em gerbox plástico contendo papel de filtro à temperatura média de $20^{\circ} \mathrm{C}$ em câmara de germinação, recebendo irrigação diária por um período de 35 dias, quando estabilizou a germinação. Segundo Borges \& Rena (1993), em geral, a faixa de temperatura entre 20 e $30^{\circ} \mathrm{C}$ é adequada para a germinação de um grande número de espécies tropicais e subtropicais. O delineamento experimental utilizado foi o inteiramente casualizado ao nível de $5 \%$ de probabilidade e com 3 repetições de 25 sementes de cada tipo de fruto.

Experimento 2 - Instalado com sementes de árvores da mesma idade (17 meses), mas com diferentes diâmetros a altura do peito (DAP): pequeno $(5,4 \mathrm{~cm})$, médio $(9,1 \mathrm{~cm})$ e grande $(13,2 \mathrm{~cm})$. As sementes foram retiradas manualmente das painas e, em seguida, colocadas para germinar em gerbox plástico contendo papel de filtro à temperatura média de $30^{\circ} \mathrm{C}$ em câmara de germinação, recebendo irrigação diária e por um período de 20 dias, quando estabilizou a germinação. $\mathrm{O}$ delineamento experimental utilizado foi o inteiramente casualizado ao nível de 5\% de probabilidade, com 4 repetições de 25 sementes cada.

Experimento 3 - As sementes foram submetidas aos seguintes tratamentos para quebra de dormência: T1testemunha; T2 - água por 24 horas (temperatura ambiente); T3 - água por 48 horas (temperatura ambiente); T4 - água a $80^{\circ} \mathrm{C}$, até esfriar; $\mathrm{T} 5-\mathrm{H}_{2} \mathrm{SO}_{4}$ por $1 / 2$ minuto sem paina; T6 $\mathrm{H}_{2} \mathrm{SO}_{4}$ por $1 / 2$ minuto com paina; $\mathrm{T} 7-\mathrm{H}_{2} \mathrm{SO}_{4}$ por 1 minuto sem paina; $\mathrm{T} 8-\mathrm{H}_{2} \mathrm{SO}_{4}$ por 1 minuto com paina; $\mathrm{T} 9$ - queima da paina sobre peneira metálica; e T10 - semeio de sementes com a paina. No tratamento T9, antes da queima da paina, esta foi espalhada em camadas finas com cerca de $3 \mathrm{~cm}$ de espessura. Depois foi ateado fogo na paina para liberação das sementes que foram coletadas em um recipiente abaixo da peneira. As sementes tratadas com ácido sulfúrico, foram lavadas em água corrente, à temperatura ambiente, com a finalidade de retirar o excesso do ácido. As sementes deste experimento foram colocadas para germinar em gerbox plástico sobre papel de filtro, em câmara de germinação à temperatura média de $25^{\circ} \mathrm{C}$ e com irrigação diária por um período de 60 dias, quando estabilizou a germinação. $\mathrm{O}$ delineamento experimental utilizado foi o inteiramente casualizado ao nível de $5 \%$ de probabilidade, com 4 repetições de 50 sementes em cada tratamento. 


\section{ACTA AMAZONICA}

Nos três experimentos, a percentagem de germinação foi obtida das contagens diárias das sementes germinadas. Por falta de padrão para a germinação desta espécie, consideram-se germinadas as sementes que emitiram $1 / 2 \mathrm{~cm}$ de comprimento da raiz primária. Posteriormente foi calculado o índice da velocidade de germinação (IVG) de cada tratamento. Para as análises de variância, os dados da percentagem de germinação foram transformados em arco seno $\sqrt{ }(x+0.05)$.

\section{RESULTADOS E DISCUSSÃO}

Experimento 1: Encontraram-se diferenças significativas entre as percentagens médias de germinação das sementes oriundas de frutos negros deiscentes $(80,0 \%)$ e as de frutos verdes (37,3\%). A germinação das sementes oriundas de frutos negros $(55,6 \%)$ e verdosos $(58,7 \%)$ não foram diferentes entre si e entre a dos frutos negros deiscentes e frutos verdes (Tabela 1).

Tabela 1 - Percentagem média de germinação $(G)$ e índice de velocidade de germinação (IVG) das sementes de Ochroma lagopus retiradas de frutos com diferentes estágios de maturação aparente*.

\begin{tabular}{lcc}
\hline \hline FRUTOS & G (\%) & IVG \\
\hline Deiscente & $80,0 \mathrm{a}$ & $2,27 \mathrm{a}$ \\
Negro & $55,6 \mathrm{ab}$ & $1,45 \mathrm{ab}$ \\
Verdoso & $58,7 \mathrm{ab}$ & $0,71 \mathrm{~b}$ \\
Verde & $37,3 \mathrm{~b}$ & $0,45 \mathrm{~b}$ \\
CV $(\%)$ & 22,36 & 39,71 \\
\hline \hline
\end{tabular}

* M édias seguidas da mesma letra, na coluna, não diferem entre si pelo teste de Tukey, ao nível de $5 \%$ de probabilidade.

O índice de velocidade de germinação das sementes de frutos deiscentes $(2,27)$ não foi diferente das de frutos negros $(1,45)$ e foi diferente daquelas de frutos verdosos $(0,71)$ e de frutos verdes $(0,45)$ (Tabela 1$)$. Isto indica que a coleta dos frutos deve ser feita com a deiscência iniciada, para que a germinação seja maior e mais rápida. A deiscência do pau-de-balsa inicia quando os frutos estão negros e com as valvas se separando, sem ocorrer a dispersão das sementes que são levadas pelo vento juntamente com a paina. Borges \& Borges (1979) relacionaram o ponto ideal de colheita com a coloração dos frutos de Copaifera langsdorfii Desf. Para Jara (1996), a melhor época para a colheita é quando o fruto está em seu máximo desenvolvimento, mas antes do amadurecimento das sementes ou antes que sejam dispersadas pela deiscência dos frutos ou consumida por insetos ou pássaros.

Experimento 2: As sementes oriundas de árvores com diferentes diâmetros, tiveram a percentagem de germinação e o índice de velocidade de germinação maiores naquelas com DAP pequeno $(97,0 \%$ e 6,5$)$, em relação as de DAP grande $(67,0 \%$ e 4,2). As sementes das árvores com DAP médio $(92,0 \%$ e 5,0$)$, não foram diferentes das de DAP pequeno e grande (Tabela 2 ).

Tabela 2 - Percentagem média de germinação $(G)$ e índice de velocidade de germinação (IVG) das sementes de árvores de Ochroma lagopus com diferentes diâmetros a altura do peito (DAP)*.

\begin{tabular}{lcc}
\hline \hline DAP $(\mathrm{cm})$ & $\mathrm{G}(\%)$ & IVG \\
\hline Pequeno $(5,4)$ & $97,0 \mathrm{a}$ & $6.5 \mathrm{a}$ \\
Médio $(9,1)$ & $92,0 \mathrm{ab}$ & $5.0 \mathrm{ab}$ \\
Grande $(13,2)$ & $67,0 \mathrm{~b}$ & $4.2 \mathrm{~b}$ \\
CV $(\%)$ & 12,48 & 21,91 \\
\hline \hline
\end{tabular}

* $\mathrm{N}$ a coluna, médias seguidas da mesma letra não diferem entre si pelo teste de Tukey, ao nível de $5 \%$ de probabilidade.

As diferenças da percentagem de germinação e do índice de velocidade de germinação entre as sementes de árvores pequenas e grandes, provavelmente, estão relacionadas ao sombreamento das copas. As árvores pequenas recebem mais sombreamento do que as árvores grandes que estão totalmente expostas ao sol e em praticamente todo o período do dia. O maior sombreamento pode manter uma maior umidade dos frutos e sementes, enquanto que uma maior insolação resseca mais o tegumento tornando-o mais rígido e dificultando mais a absorção de água no início da germinação. Neste experimento, as árvores de pau-de-balsa iniciaram a floração e frutificação aos seis meses após o plantio e no espaçamento de 3 × $3 \mathrm{~m}$, quando as copas iniciaram a se sobreporem. A alta percentagem de germinação encontrada neste experimento não está de acordo com um dos resultados encontrados por VázquezYanes (1974), onde as sementes não tratadas de pau-debalsa, tiveram baixa percentagem de germinação, inferior a $10 \%$. Varela \& Ferraz (1991) também verificaram que as sementes de pau-de-balsa apresentavam baixa percentagem de germinação (11\%). Esta diferença pode ser explicada pelo tempo de armazenamento das sementes após a coleta. Neste trabalho, as sementes foram coletadas e, após 3 dias, colocadas para germinar. Neste período, possivelmente as sementes ainda não tinham adquirido a dormência póscolheita. Segundo Jara (1996), certa espécies podem entrar em dormência em condições mais secas, já que desenvolvem uma camada dura que evita a entrada de água e consequentemente a germinação.

Experimento 3: As percentagens de germinação dos tratamentos com água à $80^{\circ} \mathrm{C}$ e com ácido sulfúrico (em 1 minuto ou $1 / 2$ minuto, com ou sem paina) produziram as maiores percentagens de germinação e índices de velocidade de germinação (Tabela 3).

As maiores médias das percentagem de germinação e índice de velocidade de germinação, variaram de $83 \%$ a $88,5 \%$ e de 7,23 a 10,75 respectivamente, indicando que a 
Tabela 3 - Percentagem média de germinação $(G)$ e índice de velocidade de germinação (IVG) das sementes de Ochroma lagopus submetidas a diferentes tratamentos pré-germinativos*.

\begin{tabular}{lcc}
\hline \hline Tratamentos & G (\%) & IVG \\
\hline $\mathrm{H}_{2} \mathrm{O} / 80^{\circ} \mathrm{C}$ & $88.5 \mathrm{a}$ & $7,23 \mathrm{ab}$ \\
$\mathrm{H}_{2} \mathrm{SO}_{4} / 1 / 2 \mathrm{~min} . \mathrm{s} /$ paina & $86.5 \mathrm{a}$ & $10,75 \mathrm{a}$ \\
$\mathrm{H}_{2} \mathrm{SO}_{4} / 1 \mathrm{~min} . \mathrm{s} /$ paina & $84.5 \mathrm{a}$ & $10,47 \mathrm{a}$ \\
$\mathrm{H}_{2} \mathrm{SO}_{4} / 1 \mathrm{~min} . \mathrm{c} /$ paina & $84.5 \mathrm{a}$ & $10,04 \mathrm{ab}$ \\
$\mathrm{H}_{2} \mathrm{SO}_{4} / 1 / 2$ min.c/ paina & $83.5 \mathrm{a}$ & $9,39 \mathrm{ab}$ \\
$\mathrm{H}_{2} \mathrm{O} / 48 \mathrm{~h}$. & $34,0 \mathrm{~b}$ & $4,69 \mathrm{bc}$ \\
$\mathrm{H}_{2} \mathrm{O} / 24 \mathrm{~h}$. & $27,0 \mathrm{~b}$ & $0,79 \mathrm{c}$ \\
Testemunha & $24.5 \mathrm{~b}$ & $1,67 \mathrm{c}$ \\
Semeio c/paina & $13,0 \mathrm{~b}$ & $0,15 \mathrm{c}$ \\
Queima da paina & $10.5 \mathrm{~b}$ & $0,89 \mathrm{c}$ \\
$\mathrm{CV}(\%)$ & 16,26 & 40,91 \\
\hline \hline
\end{tabular}

* Na coluna, médias seguidas da mesma letra não diferem entre si pelo teste de Tukey, ao nível de $5 \%$ de probabilidade.

imersão em ácido sulfúrico ou em água quente à $80^{\circ} \mathrm{C}$, aumenta e antecipa a germinação do pau-de-balsa. O ácido sulfúrico tem a função de escarificar quimicamente o tegumento tornando-o permeável à água e, também, tem a função de dissolver a paina liberando as sementes. A quebra de dormência de sementes de Parkia pendula com ácido sulfúrico por 20 minutos também foi eficaz para uma melhor e mais rápida germinação (Barbosa et al., 1984). As sementes de pau-de-balsa, tratadas com diversos tratamentos pré-germinativos e colocadas para germinar a temperatura de $30^{\circ} \mathrm{C}$, também tiveram as melhores germinações que variaram de 62 a 89\% (Varela \& Ferraz, 1991). A imersão em água também resultou em um dos melhores tratamentos em sementes de Acácia mangium, segundo Lima \& Garcia (1996). Os outros tratamentos se mostraram menos eficazes para a quebra de dormência do pau-de-balsa.

\section{CONCLUSÃO}

As sementes de pau-de-balsa germinaram melhor e mais rápido quando coletadas de frutos negros ou negros deiscentes, ou coletadas de árvores com 17 meses de plantadas e com diâmetros pequenos ou médios. As sementes recém colhidas e germinadas não apresentaram dormência tegumentar. Os melhores tratamentos para a quebra da dormência das sementes desta espécie foram com água quente a $80^{\circ} \mathrm{C}$ até esfriar ou com ácido sulfúrico por $1 / 2$ ou 1 minuto com ou sem paina. Os tratamentos com ácido sulfúrico têm a vantagem de quebrarem a dormência da semente e dissolver a paina, reduzindo a mão-de-obra com o beneficiamento e o tempo do processo germinativo.

\section{BIBLIOGRAFIA CITADA}

Alves, S.T. 1982. Estudos sobre o pau-de-balsa (AM) Ochroma pyramidale (Cav) Urb. Bombacaceae. In: Anais, Congresso Nacional de Silvicultura, SBS, São Paulo, 1982, Vol. 2.

Barbosa, A.P.; Vastano Jr., B.; Varela, V.P. 1984. Tratamentos prégerminativos de sementes de espécies florestais amazônicas. II. Visgueiro (Parkia pendula Benth. - LeguminosaeMimosoideae). Acta Amazonica, 14(1/2):280-288.

Borges, E.E. de L.; Rena, A.B. 1993. Germinação de sementes. In: Aguiar, I.B. de; Pina Rodrigues F.C.M.; Figliola, M.B. (Coord.). Sementes Florestais Tropicais. ABRATES. Brasília, p. 83-135.

Brasil. 1992. Regras para análise de sementes. Ministério da Agricultura e Reforma Agrária, Brasília. 365pp.

Freitas \& Cândido 1972. Tratamento químico para abreviar a germinação de guapuruvu (Schizolobium excelsum Vog.) e de mamoeira (Tachigalia multijuga, Bth.). Seiva. Viçosa, 76:1-10

Jara, L.F. 1996. Biología de semillas florestales. CATIE, Serie Materiales de Enseñanaza No. 36. Turrialba, Costa Rica. 32p.

Lima, D.; Garcia, L.C. 1996. Avaliação de métodos para o teste de germinação em sementes de Acacia mangium Willd. Rev. Brasileira de Sementes, 18(2):180-185

Loureiro, A.A.; Silva, M.F. 1968. Catálogo das madeiras da Amazônia., Belém, SUDAM, v.1: p.167-168

Loureiro, A.A.; Silva, M.F.; Alencar, J.C. 1979. Essências madeireiras da Amazônia. Manaus, INPA. V. 2, 187pp.

Rizzini, C.T. 1978. Árvores e madeiras úteis do Brasil, manual de dendrologia brasileira. São Paulo, Blücher. 296pp.

Tulstrup, N.P.; Magini, E. 1956. Notas sobre semillas florestales. Roma, FAO, Cuaderno de Fomento Florestal número 5.

Varela, V.P.; Ferraz, I.D.K. 1991. Germinação de sementes de paude-balsa. Pesquisa Agropecuária Brasileira, 26 (10):1685-1689.

Vasques-Yanes, C. 1974. Estudies on the germination of seeds of Ochroma lagopus. Startz. Turrialba, 24(2):176-179

Vasques-Yanes, C.; Perez-Garcia, B. 1976. Notas sobre la morfologia y la anatomia de la testa de las semillas de Ochroma lagopus Sw. Turrialba, 26(3):310-311 